\title{
IDENTIFIKASI TEKNOLOGI PENGOLAHAN SAMPAH PASAR SEDERHANA
}

\author{
Aditya Wicaksono, Yulianti Pratama, Nico Halomoan \\ Jurusan Teknik Lingkungan, Fakultas Teknik Sipil dan Perencanaan \\ Email : aditflow18@gmail.com
}

\begin{abstract}
ABSTRAK
Pasar Sederhana merupakan salah satu pasar yang berada di Kecamatan Sukajadi dimana sangat dekat dengan pemukiman dan berpotensi menimbulkan masalah di lingkungan sekitar ketika

tidak ditangani dengan benar. Mengacu pada undang- Undang No 18 Tahun 2008 tentang Pengelolaan Sampah, salah satu cara yang efektif dalam mengurangi jumlah timbulan sampah dari sumbernya di antaranya berupa memanfaatkan kembali sampah dengan teknologi yang dapat membuat sampah memiliki nilai baik ekonomi maupun fungsi. Maksud dari studi ini adalah mengidentifikasi komposisi, timbulan dan karakteristik sampah di lokasi penelitian, untuk menentukan teknologi pengolahan yang tepat sehingga mengurangi jumlah sampah yang diangkut ke TPA. Pengumpulan data dilakukan dengan cara melakukan obesrvasi, wawancara dan pengukuran dilapangan. Hasil observasi dan wawancara, Pasar Sederhana melakukan pengelolaan dimulai dari pewadahan sampah sampai pemindahan sampah dari wadah kedalam bak kontainer, untuk pengangkutan dilakukan oleh pihak PD.Kebersihan. Sampah yang dihasilkan didominasi oleh sampah organik sebesar $84 \%$, satuan timbulan sampah sebesar $0,609 \mathrm{Kg} / \mathrm{m}^{2} /$ hari dan densitas sebesar 0,178 kg/l. Dari pengukuran karakteristik didapat kadar air sebesar 77\%, karbon organik 43,55\%, NTK $0,18 \%$ dan rasio $\mathrm{C} / \mathrm{N} 242$ Berdasarkan pengukuran, sampah pasar sederhana memiliki potensi dimanfaatkan baik sebagai bahan baku pengomposan atau bahan baku biodigester. Tetapi dibutuhkan pre-treatment agar sampah pasar sederhana dapat dimanfaatkan sebagai bahan baku pengomposan ataupun biodigester.
\end{abstract}

Kata Kunci : pengolahan sampah, pengukuran, Pasar Sederhana.

\section{ABSTRACT}

Sederhana Market is one of the markets in Sukajadi sub district which is very close to the settlement area which potentially can cause problems to the environment when its management not handled carefully. Referring to Act no. 8 in 2008 on Waste Management, one of the effective ways to reduce the amount of waste from its source is to reduce waste with technology that can make waste has economic value and function. The purpose of this study is to identify the composition, waste generation and characteristics, so that the appropriate technology can be determined and the amount waste transported to landfill can be reduced. Data collected by doing an field observation, interview, and measurement. The result, Sederhana Market has a waste management sistem starting from waste handling until removal from waste collecting into container. The waste transport is handled by $P D$ Kebersihan. Waste produced is dominated by organic waste with $84 \%$, waste generation unit is $0.609 \mathrm{Kg} / \mathrm{mz} / \mathrm{day}$, and density is $0.178 \mathrm{~kg} / \mathrm{l}$. Results obtained from characteristic test, moisture content is $77 \%$, organic carbon is $43,55 \%, N T K$ is $0,18 \%$ and C/N ratio is 242. 
Based on those results, Sederhana market waste has the potential to be used either as raw material of composting or biodigester raw materials. But it requires a pre-treatment process to make Sederhana market waste can be used as raw material for composting or biodigester.

Keywords: waste processing, measurement, Sederhana Market.

\section{PENDAHULUAN}

Permasalahan sampah merupakan permasalahan umum yang masih sering dijumpai di lingkungan sekitar dan harus segera diatasi secara cermat. Permasalahan sampah terjadi karena tidak seimbangnya timbulan sampah dengan pengelolaannya.

Pasar merupakan pusat aktivitas jual beli barang-barang kebutuhan sehari- hari bagi masyarakat sehingga menghasilkan timbulan sampah. Karakteristik sampah di pasar pada umumnya didominasi oleh jenis sampah organik yang mudah mengalami penguraian menyebabkan timbulnya bau dan estetika yang kurang baik. Apabila timbulan sampah tersebut tidak dikelola dengan baik tentunya akan menyebabkan kondisi menjadi tidak nyaman, berpotensi menimbulkan sarang penyakit, dan estetika yang kurang baik.

Pasar Sederhana merupakan salah satu pasar yang berada di Kecamatan Sukajadi Kota Bandung menjadikan pasar ini sebagai salah satu sentra jual beli berbagai kebutuhan sehari-hari. Pasar Sederhana memilik luas sebesar $10.000 \mathrm{~m}^{2}$ dan memiliki 851 tempat berdagang yang terbagi antara kios dan meja. Pasar Sederhana memiliki 27 jenis dagangan dan 725 pedagang aktif yang didominasi oleh pedagang bahan pangan. Pengelolaan sampah di Pasar Sederhana masih berupa kumpul, angkut dan buang. Belum adanya pengolahan sampah di Pasar Sederhana membuat sampah menumpuk di TPS. TPS Pasar Sederhana memiliki luas sebesar $42 \mathrm{~m}^{2}$ dimana sampah yang ditampung adalah sampah pasar dan sampah domestik dari pemukiman sekitar. Luas yang dimiliki Pasar Sederhana menjadikan Pasar Sederhana memiliki potensi timbulan sampah yang besar serta lokasi yang berdekatan dengan pemukiman membuat sampah Pasar Sederhana berpotensi mengganggu estetika bahkan kesehatan warga sekitar.

Mengacu pada UU No 18 Tahun 2008 tentang pengelolaan sampah, memandang sampah sebagai sumber daya yang mempunyai nilai ekonomi dan dapat dimanfaatkan, misalnya, untuk energi, kompos, pupuk ataupun untuk bahan baku industri. Menjadikan timbulan sampah Pasar Sederhana memiliki potensi untuk diolah. Sehingga diperlukan penelitian terhadap persoalan sampah di Pasar Sederhana. Penelitian bertujuan untuk menentukan teknologi pengolahan sampah yang sesuai dengan karakteristik sampah Pasar Sederhana. Penentuan teknologi ini dimaksudkan untuk mengurangi sampah yang diangkut menuju TPA. 


\section{Metodologi}

Metode yang digunakan secara umum adalah mencakup pengumpulan data primer yang diperoleh dari hasil pengukuran, observasi langsung. Diagram alir penelitian dapat dilihat pada Gambar.1

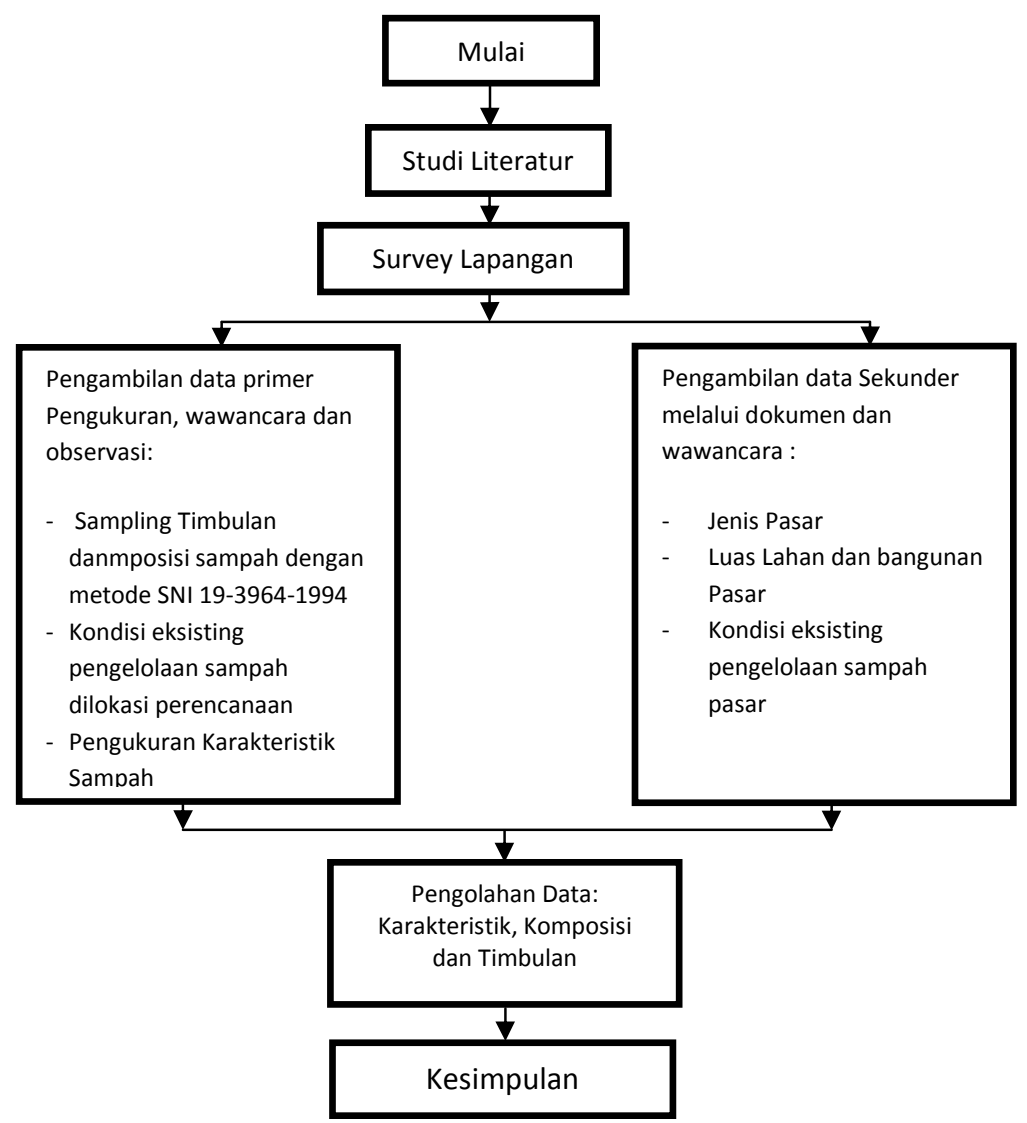

Gambar 1. Diagram alir penelitian

\section{PENJELASAN METODOLOGI}

Gambar diatas merupakan digram alir dalam pelaksanaan penelitian ini. Terdapat langkah kerja dimulai dari studi literatur, survey lapangan sampai dengan pengukuran timbulan, komposisi, dan karakteristik .

\section{Studi Literatur}

Melakukan studi terhadap referensi dan teori yang berkaitan dengan pengelolaan serta teknologi pengolahan sampah.

\section{Survey Lapangan}

Melakukan observasi terhadap pengelolaan sampah daerah yang akan dilakukan penelitian. 


\section{Pengumpulan Data}

Tahapan pengumpulan data dalam perencanaan ini terdapat dua kegiatan, yaitu pengumpulan data primer dan sekunder. Untuk data sekunder, data yang dikumpulkan yaitu berupa karateristik pasar, kondisi eksiting pasar dan kondisi eksisting pengelolaan sampah pasar. Sedangkan data primer yang dikumpulkan yaitu timbulan sampah dan karakteristik sampah baik fisik dan kimia. Lebih jelasnya dapat dilihat pada Tabel 1.

Tabel 1 Metode Pengukuran Sampah

\begin{tabular}{cccc}
\hline No & Parameter & Metode & Rujukan \\
\hline 1 & Timbulan Sampah & Gravimetri & SNI 19-3964-1994 \\
2 & Kadar Air & Gravimetri & SNI 01-3182-1992 \\
3 & Nitrogen Total Kjedahl & Kjedahl Analyzer & SNI 2801:2010 \\
4 & C-Organik & Walkey\& Black & ERASC 2002 \\
\hline
\end{tabular}

Sumber: SNI 2010, U.S EPA'S ERASC 2002

\section{Metoda Penentuan Sampel dan Timbulan Sampah}

Pada pengumpulan data timbulan sampah dibagi pada dua tahapan. Tahap pertama adalah perencanaan jumlah sampel dan tahap kedua yaitu pengambilan sampel sampah. Terpilihnya perhitungan sampel dengan SK SNI tidak lain didasari beberapa hal diantaranya:

- Jumlah sampel yang representatif

- Perhitungan didasarkan pada luas wilayah

- Biaya yang terjangkau

\section{Perhitungan Jumlah Sampel}

Berikut merupakan rumus SNI 19-3964-1995 dalam (Damanhuri D. E., 2015) yang digunakan dalam perhitungan jumlah sampel.

$$
\begin{array}{ll}
\text { As } & =\mathrm{C}_{\mathrm{nd}} \sqrt{\text { And }} \\
\mathrm{S} & =\mathrm{C}_{\mathrm{nd}} \sqrt{T s}
\end{array}
$$

dimana,

$\mathrm{A}_{\mathrm{s}} \quad=$ luas daerah sampel (ha)

$A_{\text {nd }} \quad=$ luas daerah non domestik (ha)

$\mathrm{S} \quad=$ jumlah sampel masing-masing jenis bangunan non perumahan

$\mathrm{T}=$ jumlah bangunan non perumahan

$\mathrm{C}_{\mathrm{nd}} \quad=$ koefisien non domestik $(1,2 ; 1 ; 0,8)$

Diketahui :

$A_{\text {nd }}: 3543,28 \mathrm{~m}^{2}$ ( total luas efektif dari kios dan meja, tidak termasuk jalan di dalam pasar)

Koefisien non domestik yang digunakan adalah $1,2\left(C_{n d}\right)$, diasumsikan dari hasil obeservasi selama pengumpulan data, dilihat selama observasi Pasar Sederhana selama jam operasionalnya tidak pernah sepi dan cenderung penuh. Maka dari itu diasumsikan bahwa Pasar Sederhana memiliki kepadatan yang tinggi.

Berdasarkan dari perhitungan rumus diatas didapat luas area sampling sebesar $71,43 \mathrm{~m}^{2}$, distribusi sampling $89 \%$ untuk kios dan $11 \%$ untuk meja. Setelah 
melakukan perhitungan tersebut didapat jumlah sampel sebesar 15 sampel terdiri dari 11 sampel kios dan 4 sampel meja.

\section{Hasil Pengukuran}

Pengukuran pada penelitian difokuskan pada timbulan sampah, komposisi dan karakteristik sampah Pasar Sederhana.

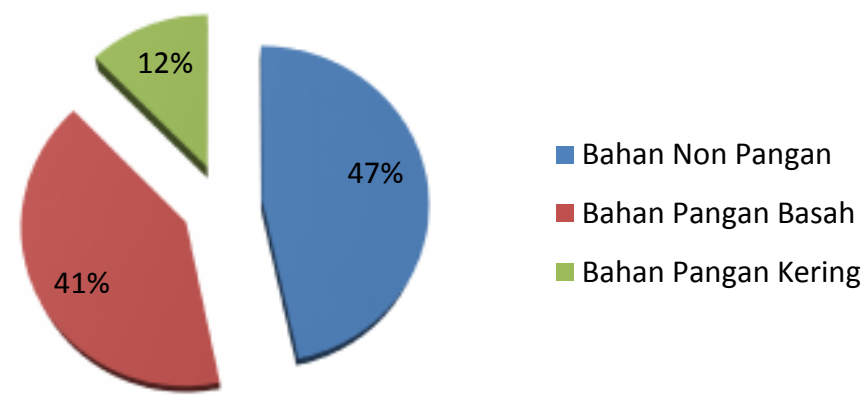

Gambar 2. Jenis Dagangan Pasar Sederhana (PD. Pasar Bermartabat, 2014)

Berdasarkan Gambar 2 pedagang di Pasar Sederhana maka didapat diagram sebagai berikut. Dimana terdapat $47 \%$ bahan non pangan, $41 \%$ pedagang bahan pangan basah, dan $12 \%$ pedagang bahan pangan kering. Jika dilihat dari data tersebut perbandingan antar jenis pedagang cenderung seingbang kecuali untuk pedagang bahan pangan kering.

Berdasarkan pengukuran di Pasar Sederhana didapatkan rata-rata timbulan sampah dalam satuan berat sebesar $0,609 \mathrm{Kg} / \mathrm{m} 2 /$ hari dan dalam satuan volume sebesar 3,447 L/m2/hari, untuk lebih jelasnya dapat dilihat pada Tabel 2.

Tabel 2 Hasil Pengukuran Timbulan

\begin{tabular}{cccc}
\hline & $\begin{array}{c}\text { Berat } \\
\mathbf{k g} / \mathbf{m}^{2} / \mathbf{h a r i}\end{array}$ & $\begin{array}{c}\text { Volume } \\
\mathbf{l} / \mathbf{m}^{2} / \mathbf{h a r i}\end{array}$ & $\begin{array}{c}\text { Densitas } \\
\mathbf{k g} / \mathbf{l}\end{array}$ \\
\hline Rata-rata & 0,609 & 3,447 & 0,178 \\
\hline
\end{tabular}

Sumber: Pengukuran 2016

Pengukuran komposisi sampah di Pasar Sederhana didapatkan organik sebesar $84 \%$, plastik $4 \%$, plastik laku jual 3\%, residu $7 \%$, kertas $2 \%$ dan B3 $0 \%$. Jika dilihat dari hasil ini maka organik sangat mendominasi komposisi dari sampah pasar ini. Pada pengukuran komposisi, komposisi sampah dibagi menjadi 6 komponen hal ini dimaksudkan untuk melihat sampah yang dapat dimanfaatkan sebagai bahan baku atau dimanfaatkan secara langsung. 


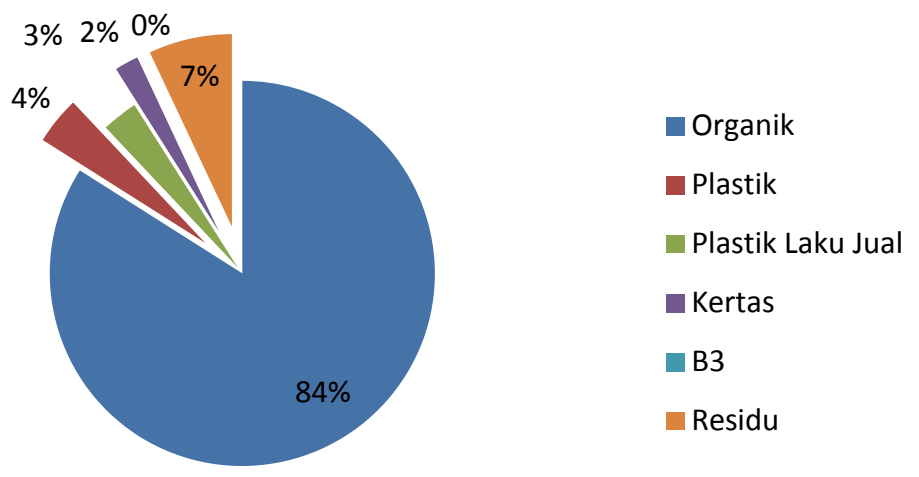

Gambar 3. Komposisi Sampah Pasar Sederhana

Pengukuran kadar air yang dilakukan didapatkan hasil sebesar $77 \%$ kadar air dan $33 \%$ kadar kering. Sedangkan dari hasil pengukuran kadar volatil didapatkan hasil sebesar $63,92 \%$ volatil dan 36,08 \% kadar abu. Hasil pengukuran karbon organik yang dilakukan selama didapat hasil sebesar $43,55 \%$. Hasil pengukuran nitrogen total kjedah yang dilakukan didapat hasil dengan $0,178 \%$.

Tabel 3 Hasil Pengukuran Karakteristik Sampah

\begin{tabular}{cccc}
\hline No & Parameter & Metode & Hasil Percobaan \\
\hline 1 & Kadar Air & Gravimetri & $77 \%$ \\
2 & Nitrogen Total Kjedahl & Kjedahl Analyzer & $43,55 \%$ \\
3 & C-Organik & Walkey\& Black & $0,18 \%$ \\
4 & C/N & - & 242 \\
\hline
\end{tabular}

Sumber: Pengukuran 2016

\section{Analisa dan Pembahasan}

Berdasarkan pengukuran dilapangan, sampah yang dihasilkan di Pasar Sederhana didominasi oleh sampah organik yaitu sebesar 84\%. Menurut SNI 19-2454-2002 pengolahan sampah dibagi dalam beberapa jenis, yaitu pengomposan, insenerasi berwawasan lingkungan, daur ulang, pemadatan, biogasifikasi. Berdasarkan literatur (Damanhuri D. E., 2015) pengolahan sampah yang cocok untuk sampah yang di dominasi oleh sampah organik salah satunya pengolahan secara biologis. Maka teknologi yang cocok digunakan sebagai sarana pengolahan sampah di Pasar Sederhana bisa berupa komposter atau juga biodigester, hal ini diperkuat jika mengacu pada hasil percobaan yang dilakukan dimana sampah Pasar Sederhana memiliki kandungan kadar air sebesar $77 \%$, volatil sebesar 63,92\%, karbon organik 43,55\%, kadar nitrogen Kjedahl sebesar 0,18\% dan rasio C/N 242. Menurut (Mustami, 2015) Kadar karbon dan nitrogen akan mempengaruhi kemampuan mikroorganisme untuk mendekomposisi sampah.

Disamping itu kadar karbon dan organik juga menunjukan tingkat kesuburan pada tanah dimana jika sampah ini diolah menjadi kompos akan memiliki hasil yang baik. Kadar 
air juga sangat berpengaruh dalam proses pengomposan atau pun pembentukan gas didalam biodigester. Misal dalam pengomposan, jika kadar airnya tinggi maka diperlukan pre-treatment guna mengurangi kadari air tesebut. Disamping itu kadar air juga mempengaruhi kelembapan didalam proses pengomposan yang nantinya mempengaruhi kinerja dari bakteri pengurai.

\section{Kadar Air}

Hasil pengukuran diperoleh kadar air untuk sampah Pasar Sederhana sebesar 87,5\%. Dalam pengomposan kadar air digunakan sebagai indikator kelembapan kondisi kompos, jika air terlalu rendah atau tinggi akan menyebabkan mikroorganisme tidak berkembang atau mati. Berdasarkan SNI 19-7030-2004 kadar air maksimal untuk bahan baku pengomposan yaitu sebesar $50 \%$.

Jika dilihat dari hasil pengukuran kadar air pada Tabel 3 sampah Pasar Sederhana melebihi batas kadar air untuk bahan baku pengomposan. Hal ini akan mempengaruhi proses pengomposan dimana pori-pori yang harusnya terisi udara akan terisi air sehingga oksigen akan berkurang yang mengakibatkan proses menjadi anaerob dan menyebabkan mikroorganisme aerob mengalami penurunan kinerja bahkan mati. Jika ditinjau dari parameter kadar air maka sampah Pasar Sederhana kurang tepat jika digunakan sebagai bahan baku pengomposan, namun jika ingin menggunakan sampah Pasar Sederhana sebagai bahan baku pengomposan harus diberi perlakuan sebelum menjadi bahan pengomposan. Perlakuan yang dimaksud adalah dengan cara di angin- anginkan sampah di tempat terbuka agar kadar air berkurang.

Menurut Brinkmann dalam (Mustami, 2015) bahwa kadar air yang baik untuk proses anaerob menggunakan biodigester yaitu lebih dari $60 \%$. Dari hasil penelitian terhadap sampah Pasar Sederhana didapat kadar air sebesar 87,5\%. Nilai tersebut memenuhi syarat kadar air ideal untuk proses anaerob menggunakan biodigester. Sehingga berdasarkan parameter kadar air sampah Pasar Sederhana dapat digunakan sebagai bahan baku untuk pengolahan anaerob menggunakan biodigester.

\section{Karbon Organik}

Dalam proses pengomposan kandungan karbon organik berfungsi sebagai sumber energi bakteri dalam pembentukan kompos. Berdasarkan SNI 19-7030-2004 kandungan karbon organik untuk bahan baku pengomposan yaitu minimal 9,80\% dan maksimal 32\%.

Hasil pengukuran karbon organik untuk sampah Pasar Sederhana sebesar 43,55\%. Berdasarkan pengukuran sampah Pasar Sederhana melebihi batas maksimal yang diperbolehkan. Hal ini akan mempengaruhi proses pembentukan kompos, karena bakteri akan kelebihan nutrisi. Namun jika ingin menggunakan sampah Pasar Sederhana makan diperlukan pre-treatment agar sampah dapat digunakan sebagai bahan baku kompos. Pretreatment yang dimaksud adalah penambahan materi yang banyak mengandung nitrogen seperti serbuk kayu atau jerami padi, hal ini dilakukan untuk menyeimbangkan rasio $\mathrm{c} / \mathrm{n}$.

Kandungan karbon organik dalam proses anaerob tidak ada syarat khusus yang harus dipenuhi, didalam bahan baku pengolahan anaerob dengan menggunakan biodigester. Namun kandungan karbon dalam bahan baku tidak boleh terlalu tinggi hal ini akan menyebabkan nitrogen akan habis terlebih dahulu. Sehingga akan memperlambat proses pengolahan dalam biodigester dan gas metan yang akan dihasilkan tidak akan maksimal (Mustami, 2015). Maka berdasarkan hasil pengukuran karbon organik sampah Pasar Sederhana dapat dijadikan sebagai bahan baku biodigester. 


\section{Nitrogen}

Nitrogen dalam proses pengomposan berfungsi sebagai sumber pembentukan struktur sel bakteri. Berdasarkan SNI 19-7030-2004 kandungan nitrogen untuk bahan baku kompos yaitu minimal $0,40 \%$.

Hasil pengukuran nitrogen sampah Pasar Sederhana sebesar 0,18\%, dari hasil pengukuran kandungan nitrogen tidak memenuhi syarat sebagai bahan baku kompos. Dengan rendahnya nitrogen maka bakteri yang berperan dalam pengomposan akan kekurangan nutrisi dan proses pembentukan kompos akan berjalan lambat. Sehingga berdasarkan parameter nitrogen sampah Pasar Sederhana kurang tepat jika diterapkan sebagai bahan baku kompos.

Dalam pengolahan anaerob menggunakan biodigester tidak ada syarat khusus untuk kadungan nitrogen. Namun kandungan nitrogen dalam bahan baku tidak boleh terlalu tinggi karena nantinya karbon akan habis terlebih dahulu oleh bakteri dan proses fermentasi (Mustami, 2015). Jika dilihat dari hasil pengukuran parameter nitrogen sampah Pasar Sederhana dapat digunakan sebagai bahan baku untuk pengolahan anaerob menggunakan biodigester.

Rasio C/N pada pengukuran karakteristik sampah Pasar Sederhana sebesar 242 ini menunjukan bahwa kadar nitrogen pada sampah Pasar Sederhana sangat kecil. Menurut (Damanhuri, 2015) untuk meningkatkan kadar nitrogen dalam sampah harus diberi tambahan materi yang banyak mengandung nitrogen. Material yang banyak mengandung nitrogen antara lain serbuk kayu, jerami padi atau kotoran ternak.

\section{Kesimpulan}

Berdasarkan hasil pengukuran diperoleh data komposisi sampah 84\% sampah organik, 4\% plastik, 3\% plastik laku jual, 7\% residu, 2\% kertas dan B3 0\%. Pengukuran karakteristik sampah didapat hasil karbon organik sebesar 43,55\%, kadar air sebesar $77 \%$, volatil sebesar 63,92\%, dan nitrogen sebesar $0,18 \%$. Pengukuran timbulan didapat satuan timbulan sampah sebesar $0,609 \mathrm{~kg} / \mathrm{m}^{2} / \mathrm{hari}, 3,447 \mathrm{l} / \mathrm{m}^{2} /$ hari dan densitas sebesar $0,178 \mathrm{~kg} / \mathrm{l}$. Berdasarkan pengukuran, sampah pasar sederhana memiliki potensi dimanfaatkan baik sebagai bahan baku pengomposan atau bahan baku biodigester. Tetapi dibutuhkan pretreatmen agar sampah pasar sederhana dapat dimanfaatkan sebagai bahan baku pengomposan atau biodigester. Berdasarkan SNI 19-7030-2004 beberapa parameter seperti kadar air, nitrogen, dan karbon organik tidak memenuhi syarat sebagai bahan baku kompos. Namun jika ingin menggunakan sampah Pasar Sederhana sebagai bahan baku maka diperlukan perlakuan tambahan seperti penurunan kadar air dan penambahan nutrisi.

\section{Daftar Rujukan}

Badan Standarisasi Nasional. (1992). Kadar Air SNI 01-3182-1992. Jakarta: Badan Standarisasi Nasional.

Badan Standarisasi Nasional. (1994). Metode Pengambilan dan Pengukuran Contoh Timbulan dan Komposisi Sampah Perkotaan SNI 19-3964-1994. Jakarta: Badan Standarisasi Nasional.

Badan Standarisasi Nasional. (2010). Pupuk Urea 2801:2010. Jakarta : Badan Standarisasi Nasional. 
Badan Standarisasi Nasional. (2004). Spesifikasi Kompos dari Sampah Organik Domestik SNI 19-7030-2004. Jakarta: Badan Standarisasi Nasional.

Badan Standarisasi Nasional. (2002). Standar Nasional Indonesia. Teknik Operasional Pengelolaan Sampah Perkotaan SNI 19-2454-2002. Jakarta: Badan Standarisasi Nasional.

Damanhuri, D. E. (2010). Diktat Pengelolaan Sampah. Bandung: Institut Teknologi Bandung. (2016). Laporan Antara Review Master Plan Persampahan. Bogor: Pemerintah Kota Bogor.

Mustami, R. (2015). Pemanfaatan Sampah Orgnaik Pasar Sebagai Bahan Baku Biodigester. PD. Pasar Bermartabat. (2014). Profil Pasar Sederhana Kota Bandung . Bandung : PD. Pasar Bermartabat. 